\title{
Burrow's graft: A simple and time-saving alternative for nasal skin repair after surgery
} Burrow grefti: Burun yerleșimli cerrahi defektlerin tamirinde basit ve zaman kazandiran bir alternatif

\section{What is a Burrow's graft?}

"Just because we can do, doesn't mean we should do." This sentence truly describes the essence of dermatologic surgery. A dermatologic surgeon should mainly aim to achieve the best functional and cosmetic results with the least complex procedures'. We believe that Burrow's graft is a wonderful example of the least complex but powerful surgical repairs. Burrow's graft was first described by Stegman in 1975. This technique relies on surgical defect closure with a fullthickness skin graft, in which the donor site is the standing cutaneous cone'2. Thus, Burrow's graft is also named the "dog ear graft."

\section{Why and when should one prefer Burrow's graft} over other methods?

Dermatologic surgeons prefer local flaps over grafts because of their superior match in color and texture with the surrounding skin. However, nose flaps are more complex repairs than grafts, which carry more risk of complications such as longer scars, scars that cross the skin tension lines, trapdoor deformity, pin-cushioning and bridging, tensioninduced contour deformities, increased risk of infection, and hematoma due to extensive undermining or occasional multistaged procedures ${ }^{3}$. Grafts have smaller incision lines and do not usually distort nasal anatomy. The most common donor sites for an upper two-thirds nose repair are the preauricular, postauricular, and periclavicular regions ${ }^{4}$. These sites possess donor skin with the nearest similarity compared with the other body sites; however, defect repair using the directly adjacent skin would provide an ideally matched skin with the same color, texture, thickness, degree of actinic damage, sun exposure, and sebaceous features. Thus, Burrow's graft provides the most satisfactory donor site for nasal defects and the entire procedure occurs at a single surgical site, the nose, which is another advantage over preauricular, postauricular, or periclavicular skin grafts ${ }^{1,4,5}$

\section{How to design the Burrow's graft?}

The first step in designing a Burrow's graft is to measure the surgical defect size and then mark the appropriate standing cone, the Burrow's triangle, with an apex angel of $30^{\circ}$, which will later serve as the graft. Some authors have stated that the length of the triangle must approach 1.5 times the original defect diameter; however, a shorter triangle was found to be sufficient in our practice ${ }^{2}$ (Figure 1). Attention should also be paid not to cross the margins of any cosmetic units or subunits while designing this triangle.

After excising the standing cone at the donor site in the subcutaneous plane, the surgical area is undermined to provide a tension-free primary closure and avoid further graft pin-cushioning. This primary closure of the donor site should start from the apex of the triangle and proceed toward the

Address for Correspondence/Yazışma Adresi: Leyla Huseynova Terzi MD, Hacettepe University Faculty of Medicine, Department of Dermatology, Ankara, Turkey Phone: +90 3123051704 E-mail: leyla.huseynova@ymail.com Received/Geliş Tarihi: 29.03.2021 Accepted/Kabul Tarihi: 01.08.2021 ORCID: orcid.org/0000-0003-3562-1491

Cite this article as: Huseynova Terzi L, Elçin G. Burrow's graft: A simple and time-saving alternative for nasal skin repair after surgery. Turkderm-Turk Arch Dermatol Venereol 2021;55:208-9 
surgical defect until the wound closure tension becomes excessive. The original defect size should be noted to partially decrease by this primary closure; thus, a smaller size graft is enough to repair the defect than is expected initially². The graft must be carefully sized to exactly fit the remaining surgical defect, and all subcutaneous tissue should be trimmed off and sutured circumferentially into the defect with minimal tension, just as in any standard full-thickness skin graft'2,5.

\section{Tips for better cosmetic outcomes}

As with any other grafts, Burrow's graft requires an appropriate vascular bed for nutrition and viability; thus, placing this graft directly over the exposed cartilage or bone is not recommended ${ }^{5}$. Ensuring proper hemostasis on the entire surgical area, including the surgical wound, donor site, and undermined area, is crucial since hematoma markedly impairs graft survival ${ }^{5}$. In case of graft necrosis, eschar must be left in place and the entire site must be kept moist with a thick layer of petrolatum. Initial postoperative necrosis is highly probable compared with the standard full-thickness skin grafts; however, the final cosmetic results are good to excellent in the majority of the Burrow's graft cases ${ }^{1}$.

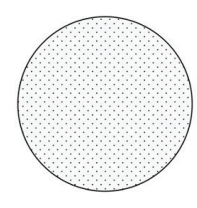

(a)

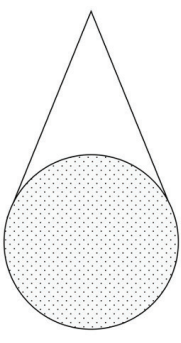

(b)

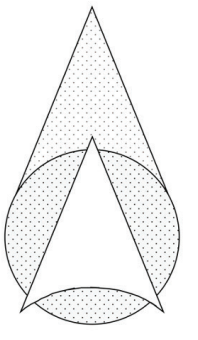

(c)

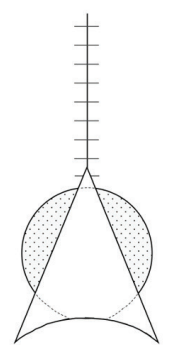

(d)

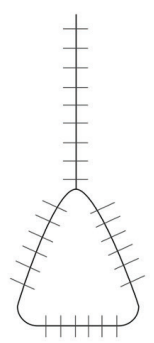

(e)
Figure 1. Burrow's graft design. (a) The surgical defect. (b) The standing cutaneous cone, which is a triangle with a $30^{\circ}$ apex angle, serves as the donor site for the Burrow's graft. (c) The excised cutaneous cone is settled onto the defect. (d) Primary closure of the secondary defect starts from the apex, proceeding from the narrow end toward the surgical defect, until the wound closure tension becomes excessive, decreasing the original defect size. (e) Thus, a smaller graft is usually needed to repair the defect than is initially expected
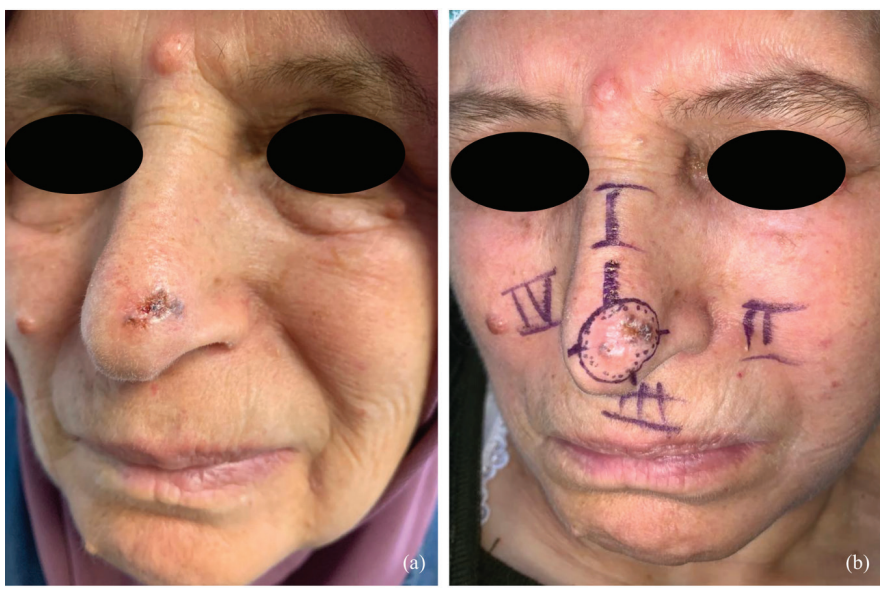

Figure 2. (a) Basal cell carcinoma located on the left nasal supratip. (b) Planning of the excision before Mohs micrographic surgery

\section{Case Report}

Presented here is the case of a 67-year-old female patient who was admitted to our clinic with a partially ulcerated nodule on her left nasal supratip with a diameter of $12 \times 8 \mathrm{~mm}$ for 5 years (Figure 2a). Punch biopsy taken from the lesion was consistent with basal cell carcinoma of a nodular and infiltrative type. The patient underwent Mohs micrographic surgery (Figure 2b), and the defect was repaired with Burrow's graft (Figure 3, 4).

Informed consent and permission were obtained from the patient for the publication of her photos and medical data.
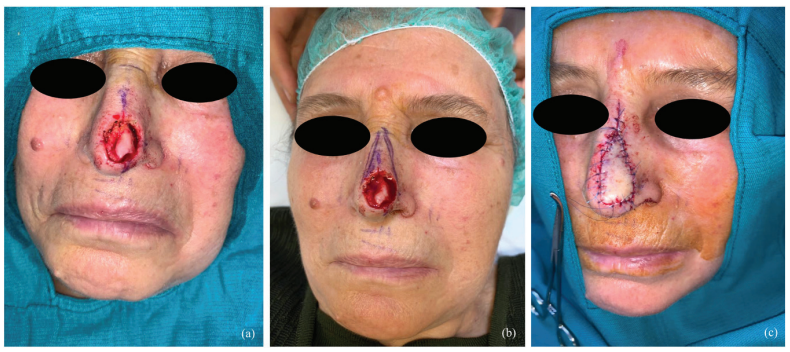

Figure 3. (a) Clear surgical margins were achieved after the first stage of Mohs micrographic surgery with a final surgical defect size of 17x15 mm. (b) Repair plan of the surgical defect with the Burrow's graft. (c) The postoperative appearance of the graft
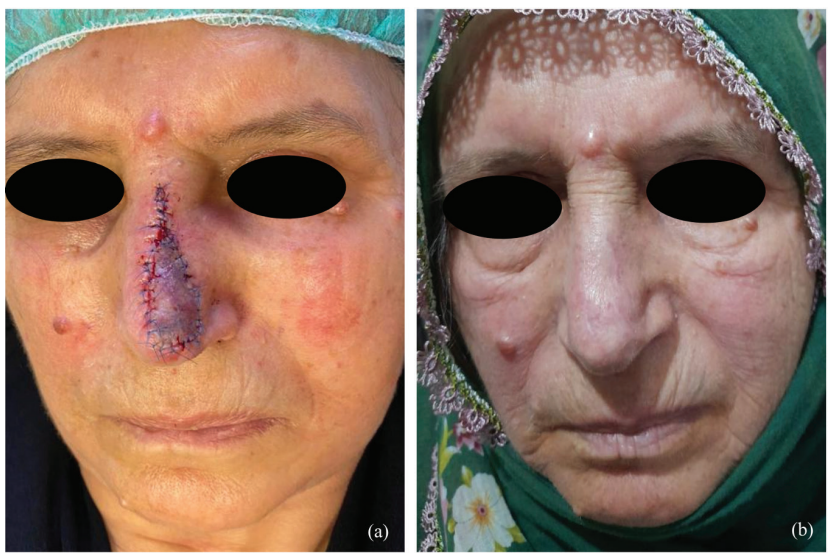

4. (a) View of the graft on the first postoperative day. Slight ecchymosis was noted on the graft area. (b) Gratifying cosmetic outcomes were observed on the grafted area in the $10^{\text {th }}$ month

\section{References}

1. Myers K, Colbert R: Burrow's graft for nasal tip defects as an alternative to more-complex reconstructive surgery following mohs surgery: A case presentation and discussion. 2017:13-5. Available at: www.aocd.org/ resource/resmgr/jaocd/contents/volume38/38-2.pdf

2. Benoit A, Leach BC, Cook J: Applications of Burow's grafts in the reconstruction of mohs micrographic surgery defects. Dermatol Surg 2017; 43:512-20

3. Jacobs MA, Christenson LJ, Weaver AL, et al.: Clinical outcome of cutaneous flaps versus full-thickness skin grafts after mohs surgery on the nose. Dermatol Surg 2010;36:23-30.

4. Gloster HM Jr: The use of full-thickness skin grafts to repair nonperforating nasal defects. J Am Acad Dermatol 2000;42:1041-50.

5. Zitelli JA: Burrow's grafts. J Am Acad Dermatol 1987;17:271-9. 